\title{
Examination of inter-rater and intra-rater reliability during retentive force measurement of different clasps using the developed small-sized retentive force measurement device
}

\author{
Hitoshi Akiyama ${ }^{1 *}$ (D), Maiko Sakamoto ${ }^{1}$, Ryoichi Akama ${ }^{2}$ and Jun Takei ${ }^{2}$
}

\begin{abstract}
Background: The design process of a removable partial denture (RPD) consists of rests, major connectors, minor connectors, denture base, and retainer. The abutment tooth contour determines the location of the retention portion of the clasp at the retention areas. The load capacity of the clasp depends on various factors such as type, the position of a clasp, tooth position, clasp length, and pullout location. As a general rule, the amount of retention required to dislodge the RPD from the supporting structure should always be the minimum necessary to resist reasonable dislodging forces. Excessive force from the clasps may cause many problems. Although there are many reports on the retentive force of cast clasps using large devices, it has not been possible to measure it using simple devices until now.

Method: The purpose of the present study is to develop a small-sized retentive force measurement device that can easily measure the retentive force of a clasp used for an RPD. It is to examine inter-rater and intra-rater reliability. A small-sized retentive force measurement device that can be easily measured in the laboratory has been developed. Using commercially available hard plaster cast, a skilled dental technician has made 10 types of cast clasps used in clinical practice using conventional techniques. Three assessors measured the retentive force of 10 types of cast clasps. To confirm the reliability, the intra-class correlation coefficients ICC $(1,1)$ and ICC $(1,3)$ of the 3 assessors were calculated, and the reliability within the assessor was examined. The inter-class correlation coefficients ICC $(3,1)$ and ICC $(3,3)$ were calculated, and the reliability of the assessors was examined.

Result: The intra-class correlation coefficients of 3 assessors are as follows: assessor 1 has ICC $(1,1)=0.971$, ICC $(1,3)=$ 0.990, assessor 2 has ICC $(1,1)=0.967$, ICC $(1,3)=0.989$, assessor 3 has ICC $(1,1)=0.962$, ICC $(1,3)=0.987$. The inter-Class correlation coefficients of 3 assessors are as follows: ICC $(3,1)=0.993$, ICC $(3,3)=0.998$. From the evaluation standard of the intraclass correlation coefficients of reliability value by ICC, it was evaluated as almost perfect and high reproducibility was confirmed.
\end{abstract}

(Continued on next page)

* Correspondence: akiyama@tky.ndu.ac.jp

${ }^{1}$ General Dentistry, The Nippon Dental University Hospital, 2-3-16 Chiyoda-ku, Fujimi, Tokyo 102-8158, Japan

Full list of author information is available at the end of the article

(c) The Author(s). 2020 Open Access This article is licensed under a Creative Commons Attribution 4.0 International License, which permits use, sharing, adaptation, distribution and reproduction in any medium or format, as long as you give appropriate credit to the original author(s) and the source, provide a link to the Creative Commons licence, and indicate if changes were made. The images or other third party material in this article are included in the article's Creative Commons licence, unless indicated otherwise in a credit line to the material. If material is not included in the article's Creative Commons licence and your intended use is not permitted by statutory regulation or exceeds the permitted use, you will need to obtain permission directly from the copyright holder. To view a copy of this licence, visit http://creativecommons.org/licenses/by/4.0/. The Creative Commons Public Domain Dedication waiver (http://creativecommons.org/publicdomain/zero/1.0/) applies to the data made available in this article, unless otherwise stated in a credit line to the data. 
(Continued from previous page)

Conclusion: The developed small-sized retentive force measurement device has reproducibility within and between the assessors.

Keywords: Abutment tooth, Retentive force, Removable partial denture, Clasp, Intraclass correlation coefficient

\section{Background}

In a treatment aiming for the functional recovery of a partially edentulous patient's masticatory system, intraoral installment of prosthetic devices functioning as artificial organs are often used. Removable partial denture (RPD) are widely used to replace missing teeth and lost alveolar tissue, thereby restoring aesthetic and function [1]. RPD should be esthetic with minimum periodontal tissue problem and sufficiently retentive to avoid begin displaced function. From the design of RPD considering occlusal pressure distribution, the design process of RPD consists of rests, major connectors, minor connectors, denture base, and retainers. The load capacity of the clasp depends on various factors such as type, the position of a clasp, tooth position, clasp length, and pullout location. The abutment tooth contour determines the location of the retention portion of the clasp at the retention areas [2]. The clasp of RPD is generally made of $0.25 \mathrm{~mm}, 0.50 \mathrm{~mm}$, and $0.75 \mathrm{~mm}$ undercuts for near and far zones [3]. As a general rule, the amount of retention required to dislodge the RPD from the supporting structure should always be the minimum necessary to resist reasonable dislodging forces. Excessive force from the clasps may cause many problems [4]. Circumferential clasps are the most frequently used direct retainers, and long term success of RPD depends on properties of clasps [5]. The retentive force is the force that works when the RPD is removed, and an appropriate force must be applied to the abutment tooth. Unfortunately, an inadequate denture design or retainer often generates an excessive retentive force to cause the movement of abutment tooth, thereby resulting in the mobility of abutment tooth. Additionally, this increases the abutment tooth's load, and eventually, the abutment tooth is lost. Inadequate use of RPD must be avoided so as not to miss a natural tooth, an integral part of a human body.

Regarding the measurement of the retentive force of the clasp for RPD, there are also several studies on clasps using the finite element method [6], on measuring the retentive force using a universal testing machine with a crosshead speed [7], on weighing the retentive force of removal and insertion cycling of clasp [8], on cyclic fatigue properties of alloy cast clasps [9], on an evaluation of retentive ability and deformation [10], on the comparison of buccal and lingual retention [11], and on clasps compared with the metal materials used [12].
These are all studies using large-scale experimental equipment, and until now, there was no equipment in the dental field that could easily measure the retentive force of a clasp of RPD.

In the present study, it is significant to present a retentive force measurement device that can be easily used in the laboratory to provide an RPD with adequate retentive force.

The purpose of the present study is to develop a small-sized retentive force measurement device that can easily measure the retentive force of a clasp used for an $\mathrm{RPD}$, and it is to examine the inter-rater and intra-rater reliability.

\section{Methods \\ Development of the small-sized retentive force measurement device}

The small-sized retentive force measurement device has a structure that detects force as a bending moment. Processing was carried out to the side where there was no chip at the tip of a commercially available band removing plier (band-removing pliers for molars 60-104, Task Co., Ltd., Tokyo, Japan). Two strain gauges (gauge length of $1 \mathrm{~mm}$ and base size of $1.4 \times 2.8 \mathrm{~mm}$, Kyowa Electronic Instruments Co., Ltd., Tokyo, Japan) for transducers were provided inside and two were given to the outside, and a cable with 1.7 calibers was welded from the terminal of the gauge towards the handles. Strain gauge has characteristics such as excellent repeatability and linearity, and it is possible to measure force, load, pressure, and displacement $[13,14]$. After the coating process, the device was covered with silicon rubber. For improvement of reproducibility, four-active-gauge method (torsion strain measurement method) was adopted, strain gauge bridge was assembled at four places, and the difference of strain generated at the four locations was output. We reduced the output error due to the difference in the loading point.

By outputting the difference between strain detection positions L1 and L2, $\varepsilon=\mathrm{F} \cdot(\mathrm{L} 1-\mathrm{L} 2) /(\mathrm{Z} \cdot \mathrm{E})$.

( $\varepsilon$ : strain output, : stress, F: force, Z: section modulus, E: Young's modulus, M: bending moment, L: distance)

Subtracting L2 from L1 is always invariable irrespective of the position of the load point; the structure was such that the magnitude of the load F could be accurately measured. For the sensor conditioner, the present 
study used a compact digital indicator (Kyowa Electronic Instruments Co., Ltd. WDS-190AS1, Tokyo, Japan) to quantify the retentive force of various clasps. The amount of distortion at the time of measurement can be converted and displayed as a retentive force. The output sensitivity was fixed at about $500 \times 10^{-6}$ strain $/ 1 \mathrm{kgf}$. The maximum peak value of the retentive force is presented on display by applying the shorter side of the small-sized retentive force measurement device attached with strain gauges on the lower arm of the retention arm of the undercut area of the retainer affixed on the abutment tooth and by vertically applying the flat-tipped edge on the occlusal surface of the abutment tooth. Figure 1 shows the developed small-sized retentive force measurement device. Figure 2 shows the structural schematic of the developed small-sized retentive force measurement device.

\section{Change to device calibration}

The strain level is measured using a measuring instrument (Kyowa Electronic Instruments Co., Ltd. PCD300B, Tokyo, Japan) to measure the strain value of the plier gauge when each load is applied to the strain sensing area of the plier of the small-sized retentive force measurement device. To confirm whether the measurement using the small-sized retentive force measurement device can be done appropriately, the strain levels $(\mu \varepsilon)$ were measured under loads of $0 \mathrm{~g}, 100 \mathrm{~g}, 200 \mathrm{~g}, 400 \mathrm{~g}$, $800 \mathrm{~g}, 1200 \mathrm{~g}, 1600 \mathrm{~g}$, and $2000 \mathrm{~g}$.

\section{Production of 10 types of cast clasps}

The 10 types of cast clasps were as follows according to the removable partial prosthodontics of McCracken [15].

An RPI clasp and a combination clasp using $0.25 \mathrm{~mm}$ undercut, a hairpin clasp, a ring clasp, an Akers clasp, a half and half clasp, a reverse backaction clasp, a

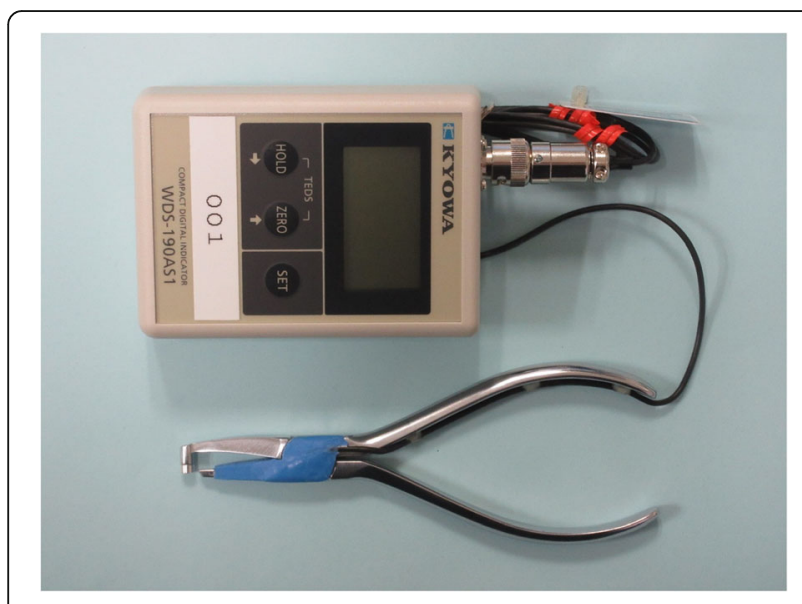

Fig. 1 The developed small-sized retentive force measurement device backaction clasp, a double Akers clasp, and an extended arm clasp using the $0.50 \mathrm{~mm}$ undercut (Fig. 3).

Using commercially available hard plaster cast, a skilled dental technician has made 10 types of cast clasps used in clinical practice using conventional techniques. Regarding the production of 10 types of cast clasps, a pre-made wax pattern for cast clasp (wax pattern MK 110-002-00, Dentaurum Co., Ltd., Osaka, Japan) was used for cast clasp with undercut depth at $0.5 \mathrm{~mm}$. A dental casting gold and silver palladium alloy (Kimpara G12, Ishihuku Metal Industry Co., Ltd., Tokyo, Japan) commonly used in dental practice in Japan were employed. Confirmation of conformity state of cast clasp was carried out using a high spot indicator (Arti-Spot ${ }^{\oplus}$, Bausch Occlusion Paper Japan, Osaka, Japan).

\section{Retentive force measurement with the small-sized retentive force measurement device}

Three assessors measured the retentive force of 10 types of cast clasps and had more than 5 years of clinical experience.

When the handle of the measurement device is closed so that the crosshead speed becomes constant, the retention arm slightly lift-up, and the separation force generated at that time is measured. Figure 4 shows the measurement situation of the small-sized retentive force measurement device.

\section{Statistical analysis}

Statistical analysis was conducted with analytical software PASW Statistics 18 (SPSS, IBM Co., Tokyo, Japan).

Intraclass correlations coefficient (ICC), one-way, twoway random effects model, ICC with $95 \%$ confidence interval $(\mathrm{Cl})$ were used to measure the inter-intra rater reliability for the quantitative measurements.

To confirm the reliability within the assessor, the intra-class correlation coefficients ICC $(1,1)$ and ICC $(1$, 3 ) of the 3 assessors were calculated. Further, to confirm the reliability between the assessors, the inter-class correlation coefficients ICC $(3,1)$ and ICC $(3,3)$ were calculated from the average of the measured values of the 3 assessors [16].

\section{Results}

Relationship between load and strain amount by the small-sized retentive force measurement device

The strain levels $(\mu \varepsilon)$ measured by the small-sized retentive force measurement device when loads of $0 \mathrm{~g}, 100 \mathrm{~g}$, $200 \mathrm{~g}, 400 \mathrm{~g}, 800 \mathrm{~g}, 1200 \mathrm{~g}, 1600 \mathrm{~g}$, and $2000 \mathrm{~g}$ were respectively added showed a straight-line increase, which can be translated into a linear function (calibration constant: $0.4610 \mathrm{~g} / 1 \mu \varepsilon$ ) (Fig. 5). 


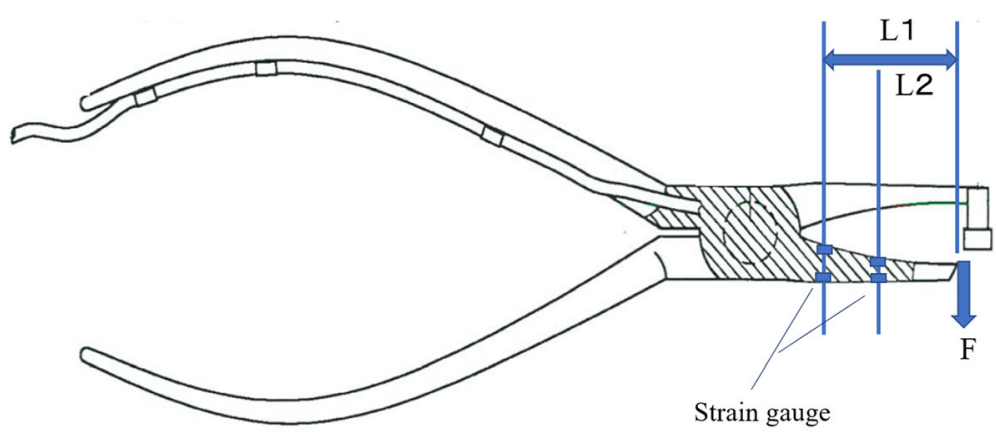

Fig. 2 The structure schematic of the developed small-sized retentive force measurement device

Retentive force measurement using the small-sized retentive force measurement device

Table 1 shows the results of the retentive force measurement of 10 types of cast clasps of 3 assessors. The intraclass correlation coefficients of 3 assessors are as follows: assessor 1 has $\operatorname{ICC}(1,1)=0.971$, ICC $(1,3)=0.990$, assessor 2 has $\operatorname{ICC}(1,1)=0.967$, ICC $(1,3)=0.989$, and assessor 3 has $\operatorname{ICC}(1,1)=0.962, \operatorname{ICC}(1,3)=0.987$ (Table 2 ). From the evaluation standard of the intra-class correlation coefficients of reliability value by ICC [17], it was
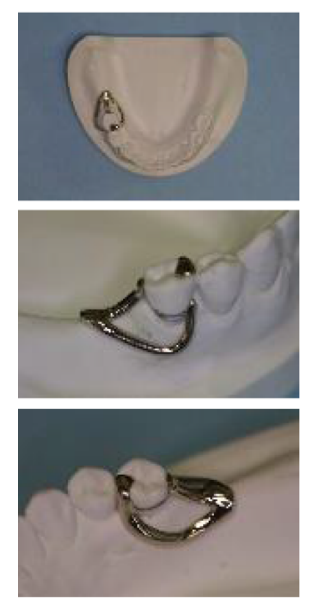

RPI clasp
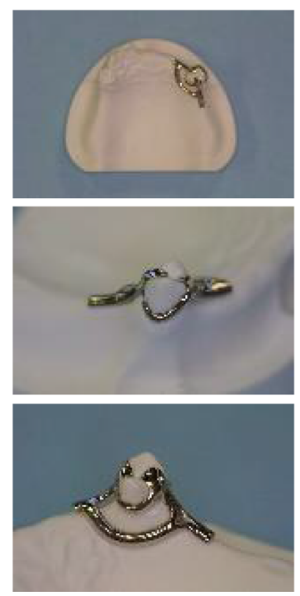

Half and half clasp
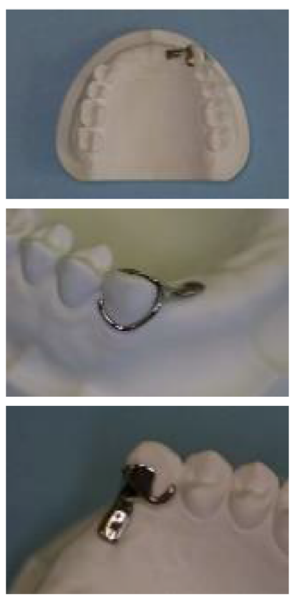

Combination wire clasp
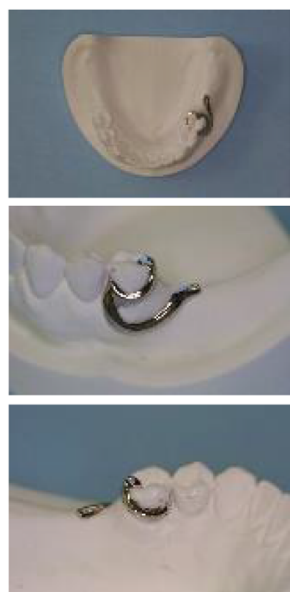

Reverse backaction clasp
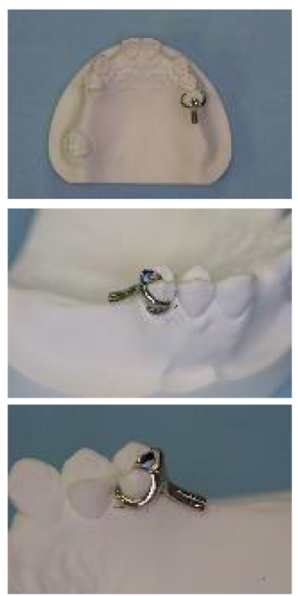

Hairpin clasp
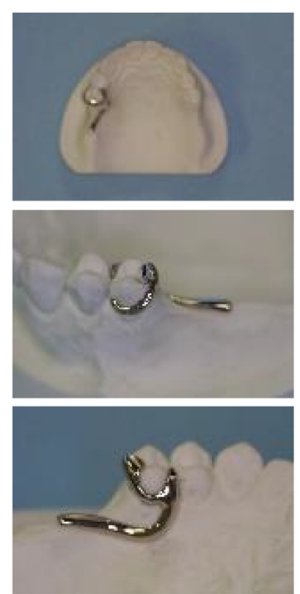

Backaction clasp
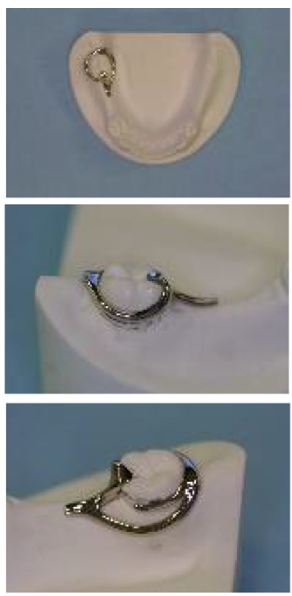

Ring clasp
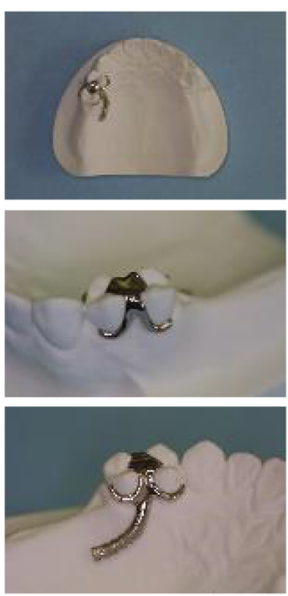

Double Akers clasp
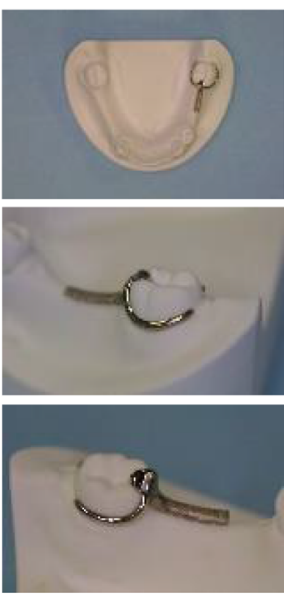

Akers clasp
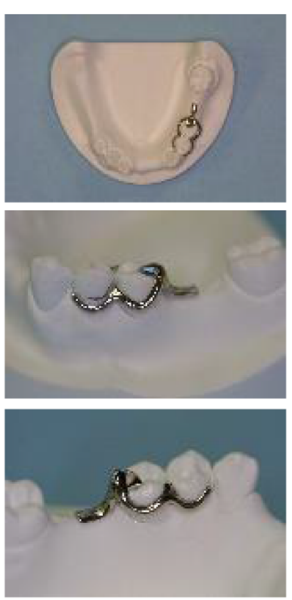

Extended arm clasp

Fig. 310 types of cast clasps used in the present study 


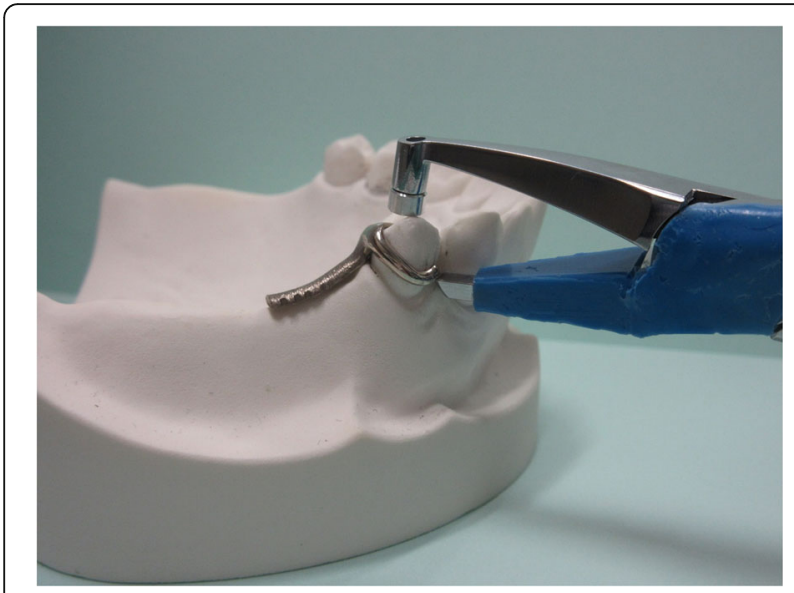

Fig. 4 The measurement situation of the small-sized retentive force measurement device

evaluated as almost perfect, and high reproducibility was confirmed. To confirm the reliability between 3 assessors, the inter-class correlation coefficients calculated from the average value of the measured values of the 3 assessors was $\operatorname{ICC}(3,1)=0.993, \quad \operatorname{ICC}(3,3)=0.998$ (Table 3). From the evaluation standard of the interclass correlation coefficients of reliability values by ICC [17], it was evaluated as almost perfect, and it was found that the reliability between assessors was high.

\section{Discussion}

In principle, the effect of support and bracing functions when wearing a partial denture. The impact of retention does not act during wearing a partial denture because the retentive force acts on the retentive arm that has entered the undercut when detaching the partial denture. When wearing a partial denture, the clasp closely conforms to the tooth surface and should not exert any force on the tooth. No burden on the abutment tooth is observed and prevents detachment of the denture. The retentive force of a clasp works only when the denture is removed. To date, the retentive force of a clasp has been reported in many laboratory studies [6-12, 18-26]. Ahmad et al. [18] mentioned that the mean retentive force for a framework engaging an undercut of $0.25 \mathrm{~mm}$ with Akers clasp was $4.77 \mathrm{~N}$. Meenakshi et al. [10] showed the clasp required $7.24 \mathrm{~N}$ for $0.25 \mathrm{~mm}$ undercut and $8.37 \mathrm{~N}$ for $0.50 \mathrm{~mm}$ undercut. Frank and Nicholls [19] concluded that 300 to $750 \mathrm{~g}$ ( 2.94 to $7.35 \mathrm{~N}$ ) represented an acceptable amount of retention for a bilateral distal extension RPD. Arda and Arikan [20] tested the retentive force of cast Akers clasp was $615.2 \pm 14.5 \mathrm{~g}$ with the undercut depth at $0.25 \mathrm{~mm}, 858.2 \pm 58.2 \mathrm{~g}$ with the undercut depth at $0.5 \mathrm{~mm}$. Bridgeman et al. [21] showed retentive forces from $5 \mathrm{~N}$ to $10 \mathrm{~N}$ would be necessary in one clasp. Wie et al. [22] showed the initial retentive force of the clasps was higher than $5 \mathrm{~N}$, the final retentive force of the $0.50 \mathrm{~mm}$ undercut clasps was approximately $5 \mathrm{~N}$. de Torres et al. [23] showed mean retentive force of RPD clasp was $8.09 \pm 3.05 \mathrm{~N}$ with $\mathrm{Co}-\mathrm{Cr}$ circumferential clasps. Tse et al. [24] found that retentive forces of $\mathrm{Co}-\mathrm{Cr}$ clasps at undercut depths of 0.25 $\mathrm{mm}, 0.50 \mathrm{~mm}$, and $0.75 \mathrm{~mm}$ were $2.34 \pm 0.23 \mathrm{~N}, 4.65 \pm$ $0.35 \mathrm{~N}$, and $7.56 \pm 0.50 \mathrm{~N}$, respectively. It has been

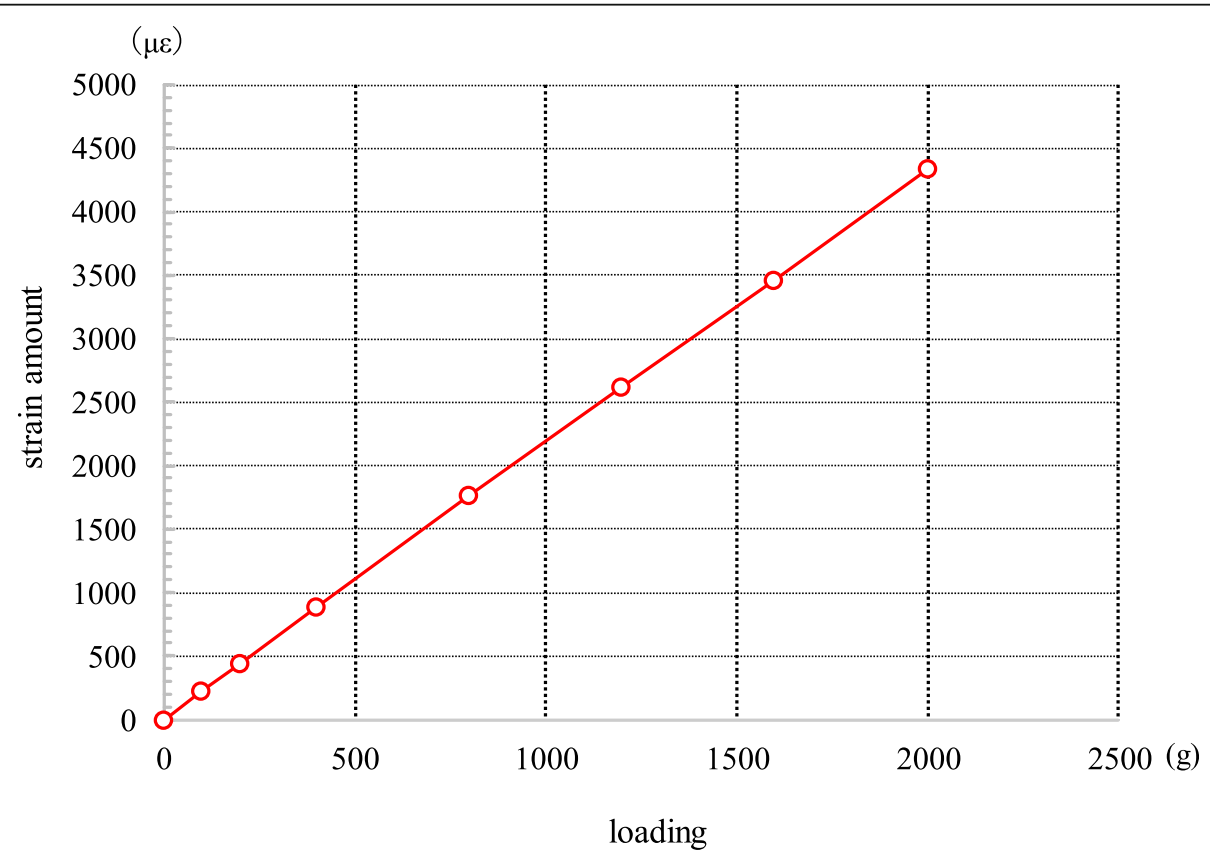

Fig. 5 Relationship between load and strain amount by the small-sized retentive force measurement device 
Table 1 The results of retentive force measurement of 10 types of cast clasps

\begin{tabular}{|c|c|c|c|c|c|c|c|c|c|c|c|}
\hline \multirow{2}{*}{$\begin{array}{l}10 \text { types of cast } \\
\text { clasps }\end{array}$} & \multirow{2}{*}{$\begin{array}{l}\text { Model } \\
\text { number } \\
\text { (Nissin } \\
\text { Co.Ltd) }\end{array}$} & \multirow{2}{*}{$\begin{array}{l}\text { Undercut } \\
\text { amount }\end{array}$} & \multicolumn{3}{|c|}{ Assessor 1} & \multicolumn{3}{|c|}{ Assessor 2} & \multicolumn{3}{|c|}{ Assessor 3} \\
\hline & & & $\begin{array}{l}1 \mathrm{st} \\
\text { time(g) }\end{array}$ & $\begin{array}{l}\text { 2nd } \\
\text { time(g) }\end{array}$ & $\begin{array}{l}\text { 3rd } \\
\text { time(g) }\end{array}$ & $\begin{array}{l}1 \mathrm{st} \\
\text { time(g) }\end{array}$ & $\begin{array}{l}\text { 2nd } \\
\text { time(g) }\end{array}$ & $\begin{array}{l}\text { 3rd } \\
\text { time(g) }\end{array}$ & $\begin{array}{l}1 \mathrm{st} \\
\text { time(g) }\end{array}$ & $\begin{array}{l}\text { 2nd } \\
\text { time(g) }\end{array}$ & $\begin{array}{l}\text { 3rd } \\
\text { time(g) }\end{array}$ \\
\hline RPI clasp & E3-522 & $0.25 \mathrm{~mm}$ & 262.4 & 218.5 & 239.3 & 197.3 & 282.6 & 230.8 & 273.7 & 230.6 & 245.2 \\
\hline $\begin{array}{l}\text { Combination wire } \\
\text { clasp }\end{array}$ & E3-583 & $0.5 \mathrm{~mm}$ & 291.4 & 235.6 & 310.2 & 256.9 & 270.6 & 217.8 & 334.3 & 295.2 & 265.3 \\
\hline Hairpin clasp & E3-545 & $0.5 \mathrm{~mm}$ & 530.7 & 513.4 & 464.5 & 517.4 & 542.1 & 616.4 & 584.2 & 489.3 & 510.7 \\
\hline Ring clasp & E3-534 & $0.5 \mathrm{~mm}$ & 632.4 & 645.3 & 680.4 & 664.6 & 632.5 & 685.5 & 673.2 & 659.2 & 599.2 \\
\hline Akers clasp & E3-541 & $0.5 \mathrm{~mm}$ & 737.4 & 659.5 & 630.5 & 690.4 & 630.2 & 604.7 & 659.3 & 690.6 & 722.4 \\
\hline Half and half clasp & E3-563 & $0.5 \mathrm{~mm}$ & 752.3 & 680.5 & 690.8 & 732.3 & 680.4 & 713.2 & 650.2 & 732.3 & 677.3 \\
\hline $\begin{array}{l}\text { Reverse backaction } \\
\text { clasp }\end{array}$ & E3-522 & $0.5 \mathrm{~mm}$ & 720.5 & 740.5 & 710.3 & 650.3 & 708.5 & 743.2 & 688.4 & 751.3 & 707.3 \\
\hline Backaction clasp & E3-567 & $0.5 \mathrm{~mm}$ & 670.3 & 732.7 & 765.4 & 703.5 & 763.2 & 740.2 & 747.3 & 688.6 & 770.2 \\
\hline Double Akers clasp & E3-530 & $0.5 \mathrm{~mm}$ & 898.2 & 810.4 & 880.6 & 840.2 & 862.5 & 780.3 & 821.3 & 879.3 & 760.1 \\
\hline Extended arm clasp & E3-546 & $0.5 \mathrm{~mm}$ & 929.3 & 870.4 & 860.4 & 880.2 & 924.4 & 826.3 & 931.3 & 889.3 & 834.2 \\
\hline
\end{tabular}

reported that the retentive force varies depending on the difference in modulus of elasticity of metal used for clasp [25]. The mechanical properties of $12 \% \mathrm{Au}-\mathrm{Pd}$ alloy and Co-Cr alloy are Vickers hardness of 280 and 365 , and tensile strength of $804 \mathrm{Mpa}$ and $938 \mathrm{Mpa}$, respectively [26]. Although there are differences in the metals used, these numerical data are similar to the measurements of the retentive force of the clasp of the present study using the small-sized retentive force measurement device.

Intraclass correlation coefficients are used in reliability studies [16, 17, 27-29]. In the present study, intraclass correlation coefficients were used to examine whether there was inter-rater reliability and intra-rater reliability when measuring the retentive force of 10 types of cast clasps. The standard of intraclass correlation coefficients is 0.0 to 0.20 for slight, 0.21 to 0.40 for fair 0.41 to 0.60 for moderate, 0.61 to 0.80 for substantial, 0.81 to 1.00 for almost perfect [17]. ICC $(1,1)$ indicates the intrarater reliability when one evaluator makes multiple evaluations. ICC $(1,3)$ indicates the reliability of the average value when one evaluator makes multiple evaluations. As a result of the present study, ICC $(1,1)$ and ICC $(1,3)$ of 3 assessors showed 0.9 or more. Accordingly, it was confirmed that the reproducibility within the assessor of this measurement device was high. ICC $(3,1)$ indicates the inter-rater reliability when multiple evaluators evaluate once. ICC $(3,3)$ indicates the reliability of the average evaluation value when multiple evaluators evaluate once. As a result of the present study, ICC $(3,1)$ and ICC $(3,3)$ of 3 assessors were both 0.9 or more, and it was found that the reliability between assessors was high. Thus, it was confirmed that the retentive force measurement by the developed small-sized retentive force measurement device has high reliability within and between the assessors.

By using the developed small-sized retentive force measurement device, it is possible to observe the retentive force of the retainers manufactured on the technician side. It will be possible to easily measure the retentive force of RPD in vitro.

\section{Limitations}

The present study is an in vitro study, and the developed small-sized retentive force measurement device of the present study measures the peeling force generated when the retentive arm is slightly lifted. This device measures the retentive force of one clasp. The RPD has several clasps, and when removing the RPD, several clasps can be lifted simultaneously in the removal direction. The device lifts the retentive arm slightly so that it can be used successfully with dentures with multiple clasps. Measurement with actual dentures is a future task.

Table 2 Intra-rater reliability of the results of retentive force measurement of 3 assessors

\begin{tabular}{lllll}
\hline & ICC $(1,1)$ & $95 \% \mathrm{Cl}$ & $\mathrm{ICC}(1,3)$ & $95 \% \mathrm{Cl}$ \\
\hline assesor 1 & 0.971 & $0.920-0.992$ & 0.990 & $0.972-0.997$ \\
assesor 2 & 0.967 & $0.911-0.991$ & 0.989 & $0.968-0.997$ \\
assesor 3 & 0.962 & $0.896-0.989$ & 0.987 & $0.963-0.996$ \\
\hline
\end{tabular}

ICC Intraclass correlation coefficient, 95\% Cl 95\% Confidence interval (lower-upper) 
Table 3 Inter-rater reliability of the results of retentive force measurement among assessors

\begin{tabular}{lllll}
\hline & ICC $(3,1)$ & $95 \% \mathrm{Cl}$ & ICC $(3,3)$ & $95 \% \mathrm{Cl}$ \\
\hline 3 assesors & 0.993 & $0.980-0.998$ & 0.998 & $0.993-0.999$ \\
\hline ICC
\end{tabular}

ICC Intraclass correlation coefficient, 95\%Cl 95\% Confidence interval (lower-upper)

\section{Conclusions}

The present study successfully developed a small-sized retentive force measurement device that enables a secure measurement of the retentive force of various clasps applied to RPDs. From examining the intraclass correlation coefficients, it was confirmed that the developed small-sized retentive force measurement device has reproducibility within and between the assessors.

\section{Abbreviations}

ICC : Intraclass correlation coefficient; Cl : Confidence interval; RPD : Removable partial denture

\section{Acknowledgements}

Not applicable.

\section{Authors' contributions}

HA contributed to the study as first author and wrote the manuscript, conception, design, acquisition, analysis, interpretation of data. MS, RA, JT contributed in designing the study. All authors contributed to the data analysis, all authors critically revised and approved the final version of the manuscript.

\section{Funding}

The present study was supported by Grant-in-Aid for Scientific Research (C) 15 K11176 from the Japan Society for the Promotion of Science, Tokyo, Japan and Project Research 2018 of The Nippon Dental University, School of Life Dentistry.

\section{Availability of data and materials}

The datasets used and/or analyzed during the current study are available from the corresponding author on reasonable request.

\section{Ethics approval and consent to participate}

The present study was approved by ethical committee of The Nippon Dental University, and the present study does not contain any studies with human participants or animal performed by any of the authors.

\section{Consent for publication}

Not applicable.

\section{Competing interests}

The author reports no conflicts of interest related to the present study.

\section{Author details}

${ }^{1}$ General Dentistry, The Nippon Dental University Hospital, 2-3-16 Chiyoda-ku, Fujimi, Tokyo 102-8158, Japan. 'Laboratory room, The Nippon Dental University Hospital, 2-3-16 Chiyoda-ku, Fujimi, Tokyo 102-8158, Japan.

Received: 4 March 2020 Accepted: 12 August 2020

Published online: 20 August 2020

\section{References}

1. Marie A, Keeling A, Hyde TP, Nattress BR, Pavitt S, Murphy RJ, Shary TJ, Dillon S, Osnes C, Wood DJ. Deformation and retentive force following invitro cyclic fatigue of cobaltchrome and aryl ketone polymer (AKP) clasps. Dent Mater. 2019:35:e113-e21.

2. Kratochvil FJ. Partial removable prosthodontics. 1st ed: WB.Saunders Co; 1988

3. Renner RP, Boucher LJ. Removable partial dentures: Chicago:Quintessence Pub.Co Inc; 1987.

4. Mourshed B, Al-Sabri FA, Qaed NA, Alaizari N, Al-Shamiri HM, Alfaqih A. Effect of clasp type and pullout location on clasp retention in different environment: in vitro study. Eur J Dent. 2017;11:216-20.

5. Turner JW, Radford DR, Sherriff M. Flexural properties and surface finishing of acetal resin denture clasps. J Prosthodont. 1999;8:188-95.
6. Reddy JC, Chintapatla SB, Srikakula NK, Juturu RK, Paidi SK, Tedlapu SK, Mannava P, Khatoon R. Comparison of retention of clasps made of different materials using three-dimensional finite element analysis. J Clin Diagn Res. 2016;10:ZC13-6.

7. Kim D, Park C, Yi Y, Cho L. Comparison of cast Ti-Ni alloy clasp retention with conventional removable partial denture clasps. J Prosthet Dent. 2004;91:374-82

8. Helal MA, Baraka OA, Sanad ME, Al-Khiary Y, Ludwig K, Kern M. Effect of clasp design on retention at different intervals using different abutment materials and in a simulated oral condition. J Prosthodont. 2014;23:140-5.

9. Cheng $\mathrm{H}, \mathrm{Xu} \mathrm{M}$, Zhang $\mathrm{H}$, Wu W, Zheng M, Li X. Cyclic fatigue properties of cobalt-chromium alloy clasps for partial removable dental prostheses. J Prosthet Dent. 2010;104:389-96.

10. Meenakshi A, Gupta R, Bharti V, Sriramaprabu G, Prabhakar R. An evaluation of retentive ability and deformation of acetal resin and cobalt-chromium clasps. J Clin Diagn Res. 2016;10:ZC37-41

11. Firtell DN, Grisius RJ. Retention of obturator-removable partial dentures: a comparison of buccal and lingual retention. J Prosthet Dent. 1980:43:212-7.

12. Rodrigues RS, Ribeiro RF, de Mattos MC, Bezzon OL. Comparative study of circumferential clasp retention force for titanium and cobalt-chromium removable partial dentures. J Prosthet Dent. 2002;88:290-6.

13. Epprecht A, Zeltner M, Benic G, Özcan M. A strain gauge analysis comparing 4-unit veneered zirconium dioxide implant-borne fixed dental prosthesis on engaging and non-engaging abutments before and after torque application. Clin Exp Dent Res. 2018;4:13-8.

14. Zhao $Y$, Zhao $Y$, Ge $X$. The development of a triaxial cutting force sensor based on a MEMS strain gauge. Micromachines. 2018;9:30.

15. Carr AB, McGivney GP, Brown DT. Direct retainers, McCracken's removable partial prosthodontics. 11th ed: Elsevier Mosby; 2000. p. 79-115.

16. Fleiss $\mathrm{J}$. Reliability of measurement, the design and analysis of clinical experiments. New York: Wiley.; 1986. p. 1-32.

17. Landis JR, Koch GG. The measurement of observer agreement for categorical data. Biometrics. 1977:33:159-74

18. Ahmad I, Sherriff M, Waters NE. The effect of reducing the number of clasps on removable partial denture retention. J Prosthet Dent. 1992;68:928-33.

19. Frank RP, Nicholls JI. A study of the flexibility of wrought wire clasps. J Prosthet Dent. 1981;45:259-67.

20. Arda T, Arikan A. An in vitro comparison of retentive force and deformation of acetal resin and cobalt-chromium clasps. J Prosthet Dent. 2005;94:267-74

21. Bridgeman JT, Marker VA, Hummel SK, Benson BW, Pace LL. Comparison of titanium and cobalt-chromium removable partial denture clasps. J Prosthet Dent. 1997:78:187-93.

22. Xie W, Zheng M, Wang J, Li X. The effect of build orientation on the microstructure and properties of selective laser melting Ti-6Al-4V for removable partial denture clasps. J Prosthet Dent. 2020;123:163-72.

23. de Torres EM, de Siqueira Damasceno II, Do Amaral BA, RCS R, ADFP C, Ribeiro RF. Effect of acetyl resin retentive arms on the retentive force of circumferential clasps: an in vitro study. J Prosthodontic Res. 2012;56:216-21.

24. Tse ET, Cheng LY, Luk HW, Chu FC, Chai J, Chow TW. Comparison of the retentive characteristics of cobalt-chromium and commercially pure titanium clasps using a novel method. Int J Prosthodont. 2006;19:371-2.

25. Bates JF. The mechanical properties of the cobalt-chromium alloys and their relation to partial denture design. Brit Dent J. 1965;119:389-96.

26. Gapido CG, Kobayashi H, Miyakawa O, Kohno S. Fatigue resistance of cast occlusal rests using co-Cr and Ag-Pd-cu-au alloys. J Prosthet Dent. 2003:90:261-9.

27. Bartko JJ. The intraclass correlation coefficient as a measure of reliability. Psychol Rep. 1966;19:3-11.

28. Shrout PE, Fleiss JL. Intraclass correlations: uses in assessing rater reliability Psychol Bull. 1979:86:420-8.

29. Koo TK, Li MY. A guideline of selecting and reporting intraclass correlation coefficients for reliability research. J Chiropractic Med. 2016;15:155-63.

\section{Publisher's Note}

Springer Nature remains neutral with regard to jurisdictional claims in published maps and institutional affiliations. 